\title{
The gtaB Marker in Bacillus subtilis 168 Is Associated with a Deficiency in UDPglucose Pyrophosphorylase
}

\author{
By H. M. POOLEY, D. PASCHOUd† AND D. KARAMATA* \\ Institut de génétique et de biologie microbiennes, rue César-Roux 19, 1005 Lausanne, Switzerland
}

(Received I May 1987; revised 3 August 1987)

Fifty-six mutants of Bacillus subtilis 168 were selected for resistance to bacteriophages $\phi 29$ or $\phi 25$. The mutations were all linked to previously described teichoic acid markers gtaA, gtaB or $g t a C$, for the first and last of which, the gene products have previously been identified. Each linkage group was shown to have two distinct phenotypes with respect to phage resistance and cell-wall galactosamine content. Recombination indexes of $0.35,0.13$ and 0.41 for groups A, B and $C$ respectively were consistent with the presence of two average-sized genes in groups $A$ and C. Correlation between genetic and phenotypic differences supported this conclusion and led to the designation of two new markers, gtaD and gtaE. Two- and three-factor transformation crosses suggested the order hisA-gtaB-gtaD-gtaA-tag-1 and gtaC-gtaE-argC. Assays for UDPglucose pyrophosphorylase and phosphoglucomutase activities in soluble extracts of representative mutants revealed that, in contrast to previous findings, the former activity was virtually undetectable in all nine group B mutants examined, suggesting that gtaB is the structural gene of this enzyme. Our results allow us to account for discrepancies with respect to previous reports. The thermosensitive mutation previously designated rodCl was shown to be $90 \%$ cotransformable with $\operatorname{tag}-1$. In view of their extremely similar phenotypes the former mutation was renamed tag-3, and the likely order obtained was gtaA-tag-3-tag-1. This suggests that many mutations associated with deformation of cell shape in $B$. subtilis are located in the region where teichoic acid genes map.

\section{INTRODUCTION}

The genetics of teichoic acid synthesis has received little attention since the identification of markers involved in glucosylation of poly(glycerolphosphate) [poly (gro $P$ )], the major wall teichoic acid in Bacillus subtilis 168 (Young, 1967; Yasbin et al., 1976), and tag-1, a thermosensitive marker associated with a decreased cell-wall content of this polymer at the restrictive temperature (Boylan et al., 1972). Recently, we have obtained interstrain $B$. subtilis $168 /$ W 23 hybrids by replacement of teichoic acid genes in strain 168 by the homologous region from strain W23 (Karamata et al., 1987). The exchanged region, large enough to encompass 20 or more average-sized genes, contained most if not all of the teichoic acid genes in this organism, including previously identified $g t a A, g t a B$ and $\operatorname{tag}-1$ markers.

Evidence has been obtained in favour of tag- 1 being involved in the synthesis of poly(gro $P$ ) (Boylan et al., 1972; Karamata et al., 1987). Characterization of three B. subtilis gta markers, associated with resistance to bacteriophage $\phi 29$, led to the probable identification of the gene products for two of them (Young, 1967): gtaA codes for the membrane-associated UDPglucose

\footnotetext{
Present address: Laboratoires Serono SA, 1170 Aubonne, Switzeriand.
}

Abbreviations: GlcNAc, $N$-acetylglucosamine; GalN, galactosamine; G1-P, glucose 1-phosphate; G1,6-DP, glucose 1,6-diphosphate; UDPG, UDPglucose; MNNG, $N$-methyl- $N^{\prime}$-nitro- $N$-nitrosoguanidine; $\quad P_{i}$, pyrophosphate; TEA, triethanolamine; PGM, phosphoglucomutase (EC 5.4.2.2); UDPGPPase, UDPglucose pyrophosphorylase (EC 2.7.7.9), poly(gro $P$ ), poly(glycerolphosphate). 
polyglycerol teichoic acid glucosyltransferase (EC 2.4.1), and gtaC for phosphoglucomutase ( $\alpha$ D-glucose 1,6-diphosphate: $\alpha$-D-glucose 1-phosphate phosphotransferase, EC 5.4.2.2; PGM). The third activity required for glucosylation, UDPglucose pyrophosphorylase (UTP : glucose 1phosphate uridyltransferase, EC 2.7.7.9; UDPGPPase) was found to be normal in all three mutant classes, leaving the structural gene of the latter enzyme to be identified. In addition, the function associated with the gtaB marker, in which activities of all three enzymes were unaltered, remained unknown.

In the present work, as in a previous study (Young, 1967), resistance to $\phi 29$ and $\phi 25$ has been exploited to obtain a large number of mutants, partly to seek answers to the above questions and also to look for new markers affecting the synthesis of teichoic acids, a class of polymers whose role(s) remains largely unknown (Baddiley, 1970: Archibald, 1974). We report genetic analyses, chemical analyses of cell walls and assays of the UDPGPPase and PGM activities in the crude soluble fraction of selected classes of mutants.

\section{METHODS}

Strains. The B. subtilis 168 strains listed in Table 1 were used. The bacteriophages employed were $\phi 29, \phi 25$ (laboratory stocks), and defective bacteriophages PBSY and PBSZ harboured by $B$. subtilis strains S31 and W23 respectively. Phage stocks were prepared as previously described (Mauël \& Karamata, 1984; Karamata et al., 1987).

Media. LA, TS plates and SAT, as well as media used for transformation and transduction experiments, were as previously described (Karamata \& Gross, 1970; Pooley \& Karamata, 1984; Karamata et al., 1987). Where necessary, amino acids ( 20 to $60 \mu \mathrm{g} \mathrm{ml}^{-1}$ final concentration), uracil and adenine $\left(100 \mu \mathrm{g} \mathrm{ml}^{-1}\right)$ were added. The citrate medium (Young, 1967) used to characterize mutant markers was modified as follows: supplementary $\mathrm{MgSO}_{4}$ was decreased from 5 to $4 \mathrm{mM}$ and the $\mathrm{pH}$ was adjusted to 7.0 with $1 \mathrm{M}-\mathrm{HCl}$ to prevent precipitation of magnesium phosphate; the addition of a trace salts solution (Schlaeppi et al., 1982) led to an increased growth rate. Amino acids were added to a final concentration of 40 or $60 \mu \mathrm{g} \mathrm{ml}^{-1}$.

Enzymes and biochemicals. Bakers' yeast glucose-6-phosphate dehydrogenase (EC 1.1.1.49), PGM, UDPGPPase, uridine diphosphoglucose (UDPG), glucose 1,6-diphosphate (G1,6-DP), sodium pyrophosphate (PP,), glucose 1-phosphate (G1-P), NADP and NADPH were all obtained from Sigma.

Mutagenesis and selection of phage-resistant mutants. A seed culture of strain L5027 (or L5028), prepared in SAT medium by inoculation from a fresh LA plate, was aerated overnight in a tube at $22^{\circ} \mathrm{C}$. Cells were mutagenized with $N$-methyl- $N^{\prime}$-nitro- $N$-nitrosoguanidine (MNNG) as described by Karamata \& Gross (1970). In a typical experiment survival was $75 \%$ and the frequency of auxotrophs was $4 \%$. After incubation overnight at room temperature, appropriate dilutions of the culture and $\phi 29$ (or $\phi 25$ ), at an m.o.i. of 100 , were spread onto LA plates and incubated for $24 \mathrm{~h}$ at $37{ }^{\circ} \mathrm{C}$. Surviving colonies, representing about $0.1 \%$ of the inoculum, were picked at random and tested for resistance to $\phi 29$ (or $\phi 25$ ) as described by Karamata et al. (1987). Out of 100 colonies examined all were resistant to the phage used.

Characterization of mutant markers. When strains are grown on a minimal medium in the absence or in the presence of glucose or galactose, in each case a growth response occurs which is characteristic for each of the markers gta A, gtaB and gtaC (Young, 1967). The use of a multiple auxotroph L5027 (or L5028) as parent strain for this study led to a marked reduction in the maximum cell density obtained on this minimal medium, relative to the $168 \operatorname{trpC2}$ strain (Young, 1967), which rendered interpretation of the different growth responses more difficult. Nevertheless, the test retained some utility in differentiating mutations belonging to various gta markers.

Genetic exchange. Methods for transformation, PBS1-mediated transduction and measurement of the recombination index have been described (Karamata \& Gross, 1970; Pooley \& Karamata, 1984).

Cell wall analysis. The procedures for cell wall preparation, phosphate analysis, hydrolysis and gas chromatography have been described elsewhere (Karamata et al., 1987).

Estimation of cell-wall galactosamine (GalN) by selective extraction from whole cells labelled with $\mathrm{N}$-acetyl[1${ }^{14} \mathrm{C}$ lglucosamine $\left(\left[{ }^{1+} \mathrm{C}\right] \mathrm{G} / \mathrm{cNAC}\right.$ ). The method of Pavlik \& Rogers (1973) was modified to give a radioassay, and whole cells rather than isolated walls were used. [Givan et al. (1982) also used whole cells to measure cell-wall GaiN chemically]. An overnight culture grown in SAT medium containing unlabelled GicNAc $(50$ or $100 \mu \mathrm{M})$ at $22^{\circ} \mathrm{C}$ was diluted to $\mathrm{OD}_{540} 0.006$ in the same medium, grown for five generations at $37^{\circ} \mathrm{C}$ and diluted 20 -fold into the same medium to which $\left[{ }^{14} \mathrm{C}\right.$ ] GlcNAc [final concentration $0.025-0.125 \mu \mathrm{Ci} \mathrm{m}^{-1}\left(0.925-4.625 \mathrm{kBq} \mathrm{m}^{-1}\right)$, in different experiments] was added. After five generations of labelling, cells $(5 \mathrm{ml})$ were collected on a membrane filter, exposed to trichloroacetic acid $(5 \%, \mathrm{w} / \mathrm{v})$ at $4{ }^{\circ} \mathrm{C}$ for about $1 \mathrm{~min}$ and washed several times with water. Cells,

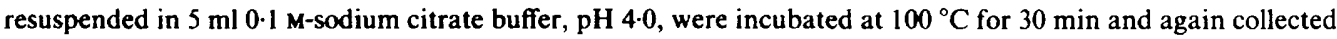
on a filter to obtain soluble and insoluble fractions. Sample preparation and counting were performed essentially as previously described by Pooley (1976). This method exploits the specific labelling of cell wall hexosamines 
Table 1. B. subtilis strains

Strain

Genotype

\begin{tabular}{|c|c|}
\hline $\begin{array}{l}\text { M22 } \\
\text { L1440 }\end{array}$ & $\begin{array}{l}\text { purA16 leuA } 8 \text { metBS ilvAI } \\
\text { Prototroph }\end{array}$ \\
\hline L5027 & hisAl argC4 leuA8 ilvaI \\
\hline L5028 & his $A 1$ argC 4 metC 3 pyrA \\
\hline 172 ts200-B & leuA8 metBS tag-1 \\
\hline Rod 113 & leuA8 tag-3 (rodCl)† \\
\hline BC7 & hisAl cysB3 trpC2 gtaC5I \\
\hline BC9 & $\operatorname{argC4} \operatorname{gtaA12}$ \\
\hline QB510 & hisAl gtaB290 \\
\hline RUB810 & lys-3 metB10 gtaB 20 \\
\hline L6118 & hisAl argC4 leuA8 ilval gtaE15I \\
\hline L6119 & hisAl argC4 leuA8 ilval gtaE152 \\
\hline L6125 & hisAl argC4 leuA8 ilval gtaEls8 \\
\hline L6145 & hisAl argC4 leuA8 ilvAl gtaBl14 \\
\hline L6147 & hisAl argC4 leuA8 ilvAl gtaBl116 \\
\hline L6162 & hisAl argC4 leuA8 ilvA1 gtaD2 \\
\hline L6165 & hisAl argC4 leuA8 ilvAI gtaDl \\
\hline L6170 & hisAl argC4 metC 3 pyra gtaEI80 \\
\hline L6179 & hisAl argC4 metC3 pyrA gtaCl89 \\
\hline L6188 & hisAl argC4 metC3 pyra gtaCl98 \\
\hline L6254 & his $A l$ argC 4 metC 3 pyrA gtaB 123 \\
\hline L6199 & hisAl argC4 metC3 pyrA gtaB 100 \\
\hline L6220 & hisAl argC4 leuA8 ilvAl gtaB 101 \\
\hline L6221 & hisAl argC4 leuA8 ilvAl gtaB 102 \\
\hline L6222 & hisAl argC4 leuA8 ilval gtaB 103 \\
\hline L6200 & hisAl argC4 ilvAl gtaB 100 \\
\hline L6225 & his 1 argC4 metC 3 gta $B^{\circ} 101$ \\
\hline L6228 & hisAl argC4 metC3 gtaBs 102 \\
\hline L6238 & his $A 1$ argC 4 gta $B^{9} 102$ \\
\hline L6240 & purA16 leuA8 ilvA1 gtaB116 \\
\hline L6256 & hisAl argC4 metC3 gtaD2 \\
\hline L6331 & purA16 leuA8 ilval gtaB515 \\
\hline L6333 & purAl6 ilvAl metB5 gtaA12 \\
\hline L6334 & purA16 leuA8 ilval gtaD1 \\
\hline L6440 & hisAl argC4 leuA8 tag-1 \\
\hline L6457 & purA16 leuA8 ilvAl tag-3 \\
\hline L6463 & purA16 metB5 tag-1 gtaA12‡ \\
\hline L6464 & his $A 1$ argC 4 metC 3 tag-1 \\
\hline L6473 & hisAl metC3 tag-1 gtaB515 \\
\hline L6475 & hisAl leuA8 tag-1 gtaD1§ \\
\hline
\end{tabular}

Reference or construction*

Karamata \& Gross (1970)

Pooley \& Karamata (1984)

Pooley \& Karamata (1984)

Pooley \& Karamata (1984)

Karamata et al. (1972)

Karamata et al. (1972)

Young et al. (1969)

Young et al. (1976)

G. Rapoport

Yasbin et al. (1976)

MNNG mutagenesis of $\mathrm{L} 5027, \phi 29^{\mathrm{r}}$

MNNG mutagenesis of L5027, $\phi 29$ r

MNNG mutagenesis of L5027, $\phi 29$ r

MNNG mutagenesis of L5027, $\phi 29$ r

MNNG mutagenesis of L5027, $\phi 29^{r}$

MNNG mutagenesis of L5027, $\phi 29^{r}$

MNNG mutagenesis of L5027, $\phi 29^{r}$

MNNG mutagenesis of L5028, $\phi 25^{r}$

MNNG mutagenesis of L5028, $\phi 25^{r}$

MNNG mutagenesis of L5028, $\phi 25^{r}$

MNNG mutagenesis of L5028, $\phi 25^{r}$

MNNG mutagenesis of L5028, $\phi 25^{r}$

MNNG mutagenesis of L5027, $\phi 25^{r}$

MNNG mutagenesis of L5027, $\phi 25$ r

MNNG mutagenesis of L5027, $\phi 25^{r}$

Congression of L6199 $\rightarrow \mathrm{L} 5027$

Congression of L6220 $\rightarrow \mathrm{L} 5028$

Congression of L6221 $\rightarrow \mathrm{L} 5028$

Congression of $\mathrm{L} 6228 \rightarrow \mathrm{L} 5027$

Congression of $\mathrm{L} 6147 \rightarrow \mathrm{M} 22$

Congression of L6162 $\rightarrow \mathrm{L} 5028$

Pooley \& Karamata (1984)

Karamata et al. (1987)

Congression of L6165 $\rightarrow$ M22

Pooley \& Karamata (1984)

Congression of Rod113 $\rightarrow$ M22

Congression of 172 ts $200-\mathrm{B} \rightarrow \mathrm{L} 6333$

Congression of L6440 $\rightarrow \mathrm{L} 5028$

Congression of L6331 $\rightarrow$ L6464

Congression of L6334 $\rightarrow \mathrm{L} 6440$

* MNNG mutagenesis was followed by direct selection for resistance to the bacteriophage indicated. Transformation crosses are denoted by an arrow pointing from donor to recipient; markers were transferred by congression with saturating concentrations of DNA $\left(1-5 \mu \mathrm{g} \mathrm{ml}^{-1}\right)$.

+ Previous designation.

¥ This strain, like another one carrying tag- 1 and gtaA 12 markers, is resistant to $\phi 25$ at $30^{\circ} \mathrm{C}$ and $37^{\circ} \mathrm{C}$.

$\S$ This strain, like several transformants with the same genotype obtained in another cross, does not grow on plates at $37^{\circ} \mathrm{C}$. At $30^{\circ} \mathrm{C}$ it forms small colonies whose morphology resembles that of $\mathrm{gtaB}$ - and $\mathrm{gtaC}$-containing strains (see Results). The resistance to $\phi 29$ is not expressed on LA.

during growth in the presence of $\left[{ }^{14} \mathrm{C}\right] \mathrm{GlcNAc}$ (Pooley, 1976). Confirmation of the specific extraction of labelled GalN is obtained by the insignificant $(1 \%$ ) release of radioactivity from gtaB and $g t a E$ strains (Table 5), whose walls lack GalN (Young, 1967, and data not shown).

Preparation of cell extracts for the assay of UDPGPPase and PGM activities. Cultures $(250 \mathrm{ml})$ were grown at $37^{\circ} \mathrm{C}$ in SAT medium supplemented with $\mathrm{MgSO}_{4}(5 \mathrm{~mm})$. Cells in the late exponential phase $\left(2 \times 10^{8} \mathrm{ml}^{-1}\right.$; $0.3 \mathrm{mg} \mathrm{dry} \mathrm{wt} \mathrm{ml}{ }^{-1}$ ) were harvested by pouring onto ice and centrifuging. In some control experiments cells were washed in various media or buffers (see below) and sedimented by centrifugation. The pellet was rinsed several times with water $\left(0^{\circ} \mathrm{C}\right)$. Thereafter, pellets rinsed or washed (by resuspension and resedimentation) were 
suspended in buffer $(2.5 \mathrm{ml})$. Suspensions were sonicated for a total of $40 \mathrm{~s}(5 \mathrm{~s}$ pulses followed by $45 \mathrm{~s}$ cooling periods) in a tube surrounded by an ice-bath. Cell debris and unbroken cells were removed by centrifugation ( 20 min at $20000 \mathrm{~g}$ ) and the supernatant was immediately assayed for UDPGPPase and PGM activities. Protein concentration in the soluble fraction, assayed with the Bio-Rad reagent (Bradford, 1976), was in the range 7-20 $\mathrm{mg}$ $\mathrm{ml}^{-1}$

In other experiments following previously described protocols, the washing medium used (at $0{ }^{\circ} \mathrm{C}$ ) was water, Spizizen's salts (as in Maino \& Young, 1974), SAT medium (with various concentrations of glucose), or one of the

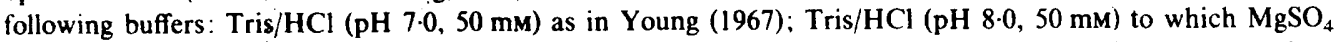
$(2.5 \mathrm{mM})$ and EDTA $(0.5 \mathrm{mM})$ had been added (Forsberg et al., 1973); Tricine (pH 8.0,100 mM) as in Edmundson \& Ashworth (1972); potassium phosphate (pH 6.5, $10 \mathrm{mM}$ ) containing EDTA (0.2 mM) (Maino \& Young, 1974) or triethanolamine (TEA) ( $\mathrm{pH} \mathrm{8.0,100} \mathrm{mM)} \mathrm{containing} \mathrm{various} \mathrm{concentrations} \mathrm{of} \mathbf{M g}^{2+}$ and EDTA (see below). Sigma triethanolamine buffer (product no. 665-5), as supplied with unspecified concentrations of $\mathrm{Mg}^{2+}$ and EDTA, was also used.

UDPGP Pase assay. The enzyme was assayed in the direction of G1-P formation, beginning with UDPG and PP. Activity was measured by coupling three reactions (Kalckar, 1955) leading to the formation of NADPH, measured by its absorbance at $340 \mathrm{~nm}$. One unit of activity represents the conversion of $1 \mathrm{nmol}$ UDPG to G1-P or an increase in $A_{340}$ of $0.0063 \mathrm{~min}^{-1}$ at $25^{\circ} \mathrm{C}$.

The reaction mixture used in most cases was as follows: $\mathrm{MgSO}_{4}(2.5 \mu \mathrm{mol})$, EDTA $(2 \cdot 2 \mu \mathrm{mol})$, NADP $(0.5 \mu \mathrm{mol})$, glucose-6-phosphate dehydrogenase ( 0.14 units), PGM ( 0.05 units), UDPG $(0.9 \mu \mathrm{mol})$, Gl, 6 -DP ( 2 or $14 \mathrm{nmol}), \mathrm{PP}_{\mathrm{i}}(1 \cdot 1 \mu \mathrm{mol})$, cell extract and TEA buffer $(\mathrm{pH} 8 \cdot 0,100 \mu \mathrm{mol})$ in a total volume of $1 \mathrm{ml}$. Stock solutions of UDPG, G1-P and G1,6-DP in TEA were either prepared freshly for each series of assays or, in a few cases, stored frozen.

UDPGPPase activity in crude extracts was stable for at least $1 \mathrm{~h}$ at $0^{\circ} \mathrm{C}$, and was proportional to total protein concentration up to about 100 units per $\mathrm{ml}$ of the reaction mixture. According to the activity present, between 50 and $600 \mu \mathrm{l}$ of extract was assayed, such that the $A_{340}$ increase was less than 0.6 absorbance units $\mathrm{min}^{-1}$. All components of the reaction mixture were essential for the maximum rate of NADPH production.

Optimal results for the reaction were obtained when all components except UDPG, G1,6-DP and PP were incubated for $10 \mathrm{~min}$ at $25^{\circ} \mathrm{C}$, followed by the addition of UDPG and G1,6-DP; 5 min later, the reaction was initiated by the addition of $\mathrm{PP}_{\mathrm{i}}$. A short lag was followed by a linear increase in $A_{340}$, lasting between $30 \mathrm{~s}$ and 1 min, after which the rate of $A_{340}$ increase slowed, to be followed by a phase of decrease in $A_{340}$. A second addition of $\mathrm{PP}_{\mathrm{i}}$ provoked a reaction similar to the initial one. Subsequent addition of $\mathbf{P P}_{\mathrm{i}}$, particularly if the quantity was doubled or tripled, gave, after a considerable lag, a linear reaction, usually slower than the initial one, which often lasted up to $10 \mathrm{~min}$.

Initial difficulties in obtaining UDPGPPase activity in extracts led to examination of the importance of various factors affecting its activity. In view of the instability of the enzyme (Young, 1967; Yasbin et al., 1976) particular attention was given to the methods of cell handling prior to breakage. When harvested cells were washed by resuspension in water, Spizizen's salts, or any of the above-mentioned buffers, the UDPGPPase activity was found to be either zero or extremely low, in contrast to previous reports. However, washing cells with SAT or the same medium with a decreased glucose content $(0.02 \%)$ yielded extracts with activities about half the values obtained with the technique finally adopted, i.e. omission of the cell washing step. Partial retention of activity when cells were washed with complete medium suggested that activity might be lost when cell metabolism was halted, in the absence of glucose, for example. The delay between harvesting and breaking cells was an important factor - we found that the longer the delay, the lower the final activity obtained. Omitting the washing step allowed a significant shortening of this delay, which was around $25 \mathrm{~min}$ in the method finally adopted. Removal of contaminating medium from the cell pellet by rinsing was, however, found to be essential, because of an interfering reaction. Indeed, cell extracts obtained without rinsing, or by deliberate addition of traces of medium, led to rapid increase of $A_{340}$ in the absence of UDPG, PP and G1,6-DP. Medium components essential for the latter reaction were glucose and phosphate, suggesting the presence of phosphokinase. We found that contaminating medium was decreased to tolerable levels by rinsing the pellet several times with water, the technique which gave highest values for UDPGPPase activity.

The choice of buffer in which cells were resuspended for sonication was also important : the use of $\mathrm{Tris} / \mathrm{HCl} \mathrm{pH}$ 7.0 (Young, 1967), Tricine pH 8.0 (Edmundson \& Ashworth, 1972), or phosphate, pH 6.5 (Maino \& Young, 1974) led to low or zero activities. TEA alone (pH 8.0, $100 \mathrm{~mm})$, or with $\mathrm{MgSO}_{4}(2.5 \mathrm{~mm})$ and EDTA $(2.2 \mathrm{mM})$ (the buffer finally adopted), gave the highest activities consistently.

The choice of buffer used in the assay mixture had less influence on the final result, and Tris pH 8.5 and TEA gave comparable values. However, the relative concentrations of $\mathbf{M g}^{2+}$ and EDTA were found to be extremely important. With $\mathrm{Mg}^{2+}$ a 2.5 or $5 \mathrm{~mm}$ and EDTA at $0.5 \mathrm{mM}$, UDPGPPase activity was barely detectable or absent. With $\mathrm{Mg}^{2+}$ at 2.5 or $5 \mathrm{mM}$ and EDTA at 2.2 or $4.5 \mathrm{mM}$, respectively, UDPGPPase was readily detectable. The Sigma TEA buffer, as supplied with $\mathrm{Mg}^{2+}$ and EDTA of unspecified concentrations, when used in the assay mixture gave results comparable to those obtained in the last two conditions, and was employed in some cases. 
Table 2. Distribution of $\phi 29 r$ mutants into linkage groups

$\phi 2^{9}$ mutants were distributed into linkage groups by PBS1 co-transduction with reference markers to which previously isolated gta mutations were shown to be linked (Young et al., 1969). The homogeneity of each group was assessed by growth on different carbon sources in liquid media (Young, 1967), and by their distinctive colony morphology.

$\begin{array}{lllcc}\begin{array}{c}\text { Linkage } \\ \text { group }\end{array} & \begin{array}{l}\text { Reference } \\ \text { mutation }\end{array} & \begin{array}{c}\text { Colony } \\ \text { morphology }\end{array} & \begin{array}{c}\text { No. of } \\ \text { mutations (\%) }\end{array} & \begin{array}{c}\text { Highest } \\ \text { recombination } \\ \text { index }\end{array} \\ \text { gtaA } & \text { gtaA12 } & \text { Rough (wild-type) } & 10(18) & 0 \cdot 45 \\ \text { gtaB } & \text { gtaB515 } & \text { Smooth } \dagger & 16(29) & 0 \cdot 13 \\ \text { gtaC } & \text { gtaE151 } & \text { Smooth } \dagger & 30(53) & 0 \cdot 41\end{array}$

\footnotetext{
- To determine the maximum distance between gta markers within each group, mutations with highest and lowest PBS1 co-transfer indexes with the reference marker were chosen, and their recombination indexes determined by transformation. Five to ten crosses were performed in each case. Allele numbers giving the highest recombination indexes to the reference mutations were gtaD2, gtaB 103 and gtaC 189 respectively.

+ Such colonies were small, shiny, raised and round.

¥ The gtaC linkage group contains two genes (see Results); the second is designated gtaE.
}

PGM assay. The activity was measured in the direction of glucose 6-phosphate formation, starting from G1-P. Coupling with glucose 6-phosphate dehydrogenase activity leads to formation of NADPH, measured as $A_{340}$. One unit was defined as for UDPGPPase (see above). Crude extracts were prepared as for the UDPGPPase assay and the PGM activity was determined by two methods, based on those of (a) Forsberg et al. (1973) and (b) Maino \& Young (1974). In the method usually used $(a)$, the reaction mixture was: glucose-6-phosphate dehydrogenase $(0.05$ units) G1-P ( $1 \mu \mathrm{mol}), \mathrm{Gl}, 6-\mathrm{DP}(2 \mathrm{nmol}), \mathrm{NADP}(1 \mu \mathrm{mol}), \mathrm{MgSO}_{4}(2 \cdot 5 \mu \mathrm{mol})$ EDTA $(2 \cdot 2 \mu \mathrm{mol})$ and TEA (pH 8.0, $100 \mu \mathrm{mol})$ in a total volume of $1 \mathrm{ml}$. The reaction was initiated by addition of Gl-P to the remaining components prewarmed to $25^{\circ} \mathrm{C}$. Method $(b)$, used occasionally, was as follows. Between 50 and $600 \mu l$ cell extract in TEA buffer ( $\mathrm{pH} 8.0,100 \mathrm{mM}$ ) containing $\mathrm{MgSO}_{4}(2.5 \mathrm{mM})$ and EDTA $(2.2 \mathrm{mM})$ was incubated for $15 \mathrm{~min}$ at $25^{\circ} \mathrm{C}$. Then, glucose-6-phosphate dehydrogenase (0.05 units) G1,6-DP (17 nmol), NADP (1 $\mu$ mol) and the abovementioned buffer, prewarmed to $25^{\circ} \mathrm{C}$, were added to give a total volume of $0.99 \mathrm{ml}$. The reaction was initiated by the addition of G1-P $(1 \mu \mathrm{mol})$. With both methods PGM activity was comparable irrespective of the buffer used in cell washing or sonication. With method $(b)$ it was confirmed that preincubating the extracts for $15 \mathrm{~min}$ at $25^{\circ} \mathrm{C}$, prior to substrate addition, increased the measured activity several fold.

During the assays of both UDPGPPase and PGM, the NADPH formed is degraded by an NADPH oxidase present in crude extracts (Young, 1967; Yasbin et al., 1976). This activity was measured by the decrease in $A_{340}$ following addition of NADPH to crude extracts prepared for the assay of UDPGPPase.

\section{RESULTS}

\section{Preliminary characterization of $B$. subtilis mutants resistant to phage $\phi 29$}

In a search for new genetic determinants involved in teichoic acid synthesis, a collection of mutants resistant to bacteriophage $\phi 29(\phi 29)$ were obtained by direct selection from a mutagenized population of $B$. subtilis 168 . Their relatedness to previously isolated and mapped $\phi 29^{\mathrm{r}}$ mutations, gtaA, gtaB and $g t a C$, all involved in glucosylation of poly(gro $P$ ), was first ascertained by PBS 1 transduction of 56 mutants chosen at random (Table 2). Thirty mutations were linked to $\operatorname{argC}$, to which the gtaC marker has been shown previously to be linked (Young $e t$ al., 1969). The remaining 26 mutations were about $50 \%$ cotransducible with his $A$, i.e. they mapped in the region containing gta $A$ and gtaB markers. Distinction between mutants belonging to the latter groups was tentatively achieved on the basis of their growth characteristics in liquid media on appropriate carbon sources (see Methods). It appeared that 10 strains were of the gtaA type whereas 16 were gtaB-like (data not presented). The colony morphology on TS medium provided a useful means of distinguishing $g t a A$ strains from other classes: all 10 putative gtaA strains formed rough colonies, indistinguishable from the $\phi 29-$ sensitive parent, whereas gtaB and gtaC strains grew as small, raised, more or less shiny and 
Table 3. Phage resistance pattern of gta mutants

\begin{tabular}{|c|c|c|c|c|}
\hline \multirow{2}{*}{$\begin{array}{l}\text { Linkage } \\
\text { group }\end{array}$} & \multicolumn{4}{|c|}{ Sensitivity/resistance* to phage: } \\
\hline & $\phi 29$ & $\phi 25$ & PBSY & PBSZ \\
\hline A & - & + & - & + \\
\hline D & - & + & + & + \\
\hline B & - & - & - & - \\
\hline $\mathrm{B}^{9}$ & - & - & + & + \\
\hline $\mathrm{C}$ & - & - & - & + \\
\hline $\mathrm{E}$ & - & - & - & - \\
\hline \multicolumn{5}{|c|}{ Total examined } \\
\hline
\end{tabular}

\footnotetext{
* + and - indicate sensitivity and resistance respectively.

+ Phage resistance pattern identical to that of the reference mutation gtaA12 (Young, 1967).

$\ddagger$ Phage resistance pattern identical to that of the reference mutation gtaB290 (Young, 1967).

$\S$ These strains were obtained by selection for $\phi 25$ resistance. gtaB mutations include gtaB 101, gtaB 102 and gtaB 103 . gtaC mutations are gtaC 189 and gtaC 198 .

\| The phage resistance pattern of strain BC7 (gtaC5l) was identical to this class.
}

round colonies. Thus, at this stage, all $\phi 29^{r}$ mutants identified here appeared, both genetically and phenotypically, to be related to previously described gta mutants (Young, 1967; Yasbin et al., 1976).

To estimate the size of linkage groups A, B and C we determined, for each of them, recombination indexes between mutations which gave the smallest and the highest co-transfer indexes in PBSI transduction experiments (see above). The highest recombination indexes, obtained by transformation, were $0 \cdot 35,0.13$ and 0.41 for linkage groups $A, B$ and $C$ respectively (Table 2). Since a recombination index of $0 \cdot 2$ corresponds to an average-sized gene, coding for a $40 \mathrm{kDa}$ protein (Bodmer \& Ganesan, 1964; Henner \& Hoch, 1980), group B probably consists of only one gene, whereas groups $A$ and $C$ could well contain more than one gene. It is not surprising that the latter marker, associated with PGM deficiency (Young, 1967), should contain two genes, at least. Indeed, SDS-PAGE analysis of $B$. subtilis preparations of PGM, an important enzyme involved in glycolysis as well as in the synthesis of many polysaccharides, revealed a complex pattern of polypeptide bands (Maino \& Young, 1974). In Neurospora, two genes are required for formation of the PGM enzyme complex (Mishra \& Tatum, 1970).

\section{Phage resistance spectrum of gta mutations}

To identify possible new classes among mutants belonging to the linkage groups described above, we examined the resistance of different $\phi 29^{\mathrm{r}}$ (or $\phi 25^{r}$ ) mutants to both phages as well as to defective bacteriophages PBSY and PBSZ (Table 3). Among mutants examined belonging to group A, two were sensitive to all phages but $\phi 29$, whereas the remaining seven were resistant to $\phi 29$ and PBSY, as was a strain containing the previously identified marker gtaA12 (Young, 1967). The close linkage between mutations harboured by the first two strains (recombination index less than $0 \cdot 1$ ) and their apparent distance (recombination index $0 \cdot 3$ ) from remaining gta $\mathrm{A}$ mutations (including gtaA12) suggest that they belong to a separate gene, designated gtaD. Screening of linkage group $B$ revealed that five of the strains examined were resistant to all four phages whereas four were sensitive to both PBSY and PBSZ. Nevertheless, the highest recombination index of group B is too small (Table 2) to warrant assigning these phenotypes to different genes. Results for enzyme activities provide further support for considering that all gtaB mutations belong to the same gene (see below). However, since these differences in phage sensitivity were found to be correlated with cell-wall GalN content (see below) we have designated mutations with the latter phenotype gta $B^{9}$. Finally, group $C$ mutants also split into two classes: ten were resistant to all phages whereas two were sensitive to PBSZ. The latter markers mapped at one extreme of this relatively large linkage group and were different from all other mutants in this group in their UDPGPPase activity (see below). These differences, and 
Table 4. Cell wall teichoic acid composition of gta mutants

Results, obtained by GLC, are given in $\mu \mathrm{mol}\left(\mathrm{mg}\right.$ cell wall) ${ }^{-1}$ for all components. Phosphate was determined colorimetrically (Ames \& Dubin, 1960).

$\begin{array}{llcccc}\text { Strain } & \text { Mutation } & \text { Phosphate } & \text { Glycerol } & \text { Glucose } & \text { GalN } \\ \text { M22 } & & 1.28 & 0.84 & 0.45 & 0.16 \\ \text { L6333 } & \text { gtaA12 } & 1.43 & 0.85 & 0.15 & 0.20 \\ \text { L6334 } & \text { gtaD1 } & 1.3 & 1.0 & 0.23 & 0.19 \\ \text { L6331 } & \text { gtaB515 } & 1.5 & 0.92 & 0.04 & 0.02 \\ \text { L6225 } & \text { gtaB } 101 & 1.33 & 0.84 & 0.06 & 0.04 \\ \text { L6228 } & \text { gtaB } 102 & 1.05 & 0.67 & 0.06 & 0.07\end{array}$

\section{Table 5. GalN-containing teichoic acids in cell walls of strains carrying different gta markers}

Cells, continuously grown with $\left[{ }^{4} \mathrm{C}\right] \mathrm{GlcNAc}$ to specifically label cell wall hexosamines, were precipitated by $5 \%$ TCA and the GalN-containing teichoic acids were extracted by heating for $30 \mathrm{~min}$ at $100^{\circ} \mathrm{C}$ at $\mathrm{pH} 4$. Results were corrected for radioactivity incorporated into protein as previously described (Pooley, 1976).

$\begin{array}{lcc}\text { Marker } & \begin{array}{c}\text { No. of } \\ \text { strains } \\ \text { examined }\end{array} & \text { GalN* }^{*} \\ \text { gta }^{+} & 2 & 15.3 \pm 1.5 \\ \text { gtaA } & 6 & 20.7 \pm 1.4 \\ \text { gtaD } & 2 & 18.4 \pm 1.5 \\ \text { gtaB } & 9 \dagger & 0.9 \pm 0.1 \\ \text { gtaB } & 3 & 4.5 \pm 0.4 \\ \text { gtaC } & 2 \ddagger & 9.5 \\ \text { gtaE } & 6 \S & 3.3 \\ & & 0.9 \pm 0.1\end{array}$

- Expressed as a percentage of the total radioactivity incorporated into cell-wall hexosamines. The values are means \pm standard error; a minimum of two independent measurements were made for each strain examined.

† Includes strains RUB810 (gtaB20) and QB510 (gtaB290).

$\ddagger$ Strains L6188 and L6179.

$\S$ Strain BC7 was identical to this class.

those in cell-wall GalN content (see below), led to the mutations in the former group being assigned to a new marker, designated gtaE. This is in agreement with the conclusion, made above on genetic grounds, that group $\mathrm{C}$ consists of at least two genes.

\section{Anionic polymer components in cell walls of gta mutants}

The presence of different phage-resistance phenotypes among all linkage groups suggested the existence of differences in cell-wall composition. Accordingly, cell walls, isolated from several mutant classes, were hydrolysed and subjected to GLC analysis. Results, in agreement with previous findings, showed that all mutants examined were glucose deficient, although to various degrees, whereas their phosphorus and glycerol contents were comparable to those of the wild-type (Table 4). Further analyses (F. Fiedler, personal communication) have revealed that walls from both $g t a A$ and $g t a D$ as well as $g t a B^{\mathcal{G}}$ mutants were devoid of the glucosylated form of poly $($ gro $P$ ). This confirms the previous conclusion (Young, 1967) that glucosylated poly (gro $P$ ), absent from all classes of $g t a$ mutants examined, forms an essential part of the $\phi 29$ receptor. The substantial amounts of glucose associated with mutations gtaA12 and gtaDl may well be correlated with a wild-type content of the GalN-glucose phosphate polymer (Shibaev et al., 1973; Archibald, 1980). Indeed, these mutations were associated with wild-type levels of GalN and between one-third and one-half of the glucose of a $\mathrm{gta}^{+}$strain, in contrast to the much lower contents of these components in three gtaB group mutants. 


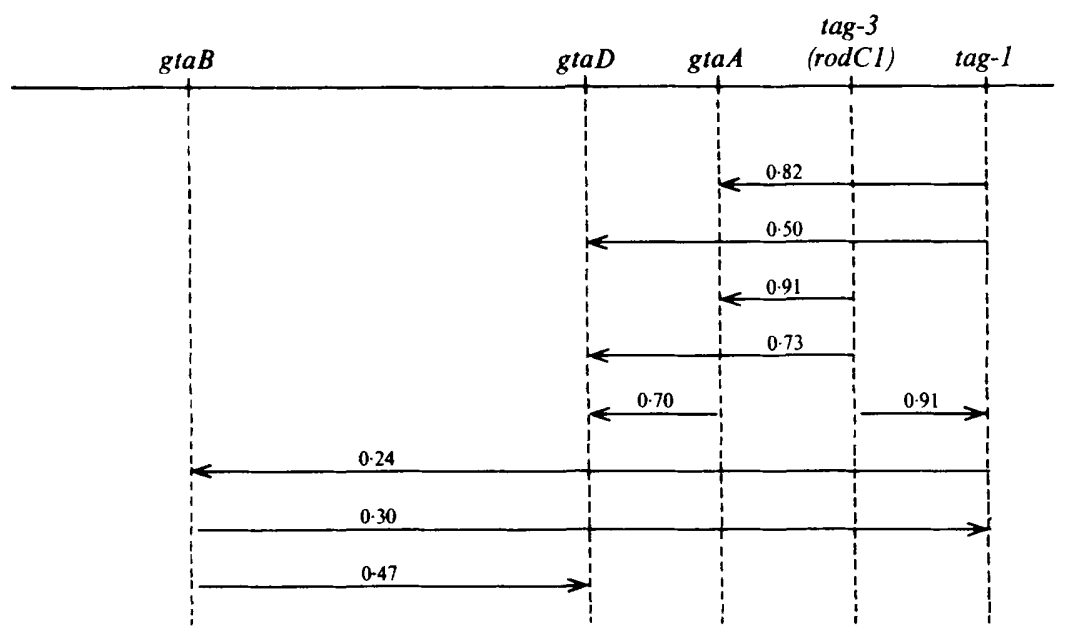

Fig. 1. Probable order of gta and tag markers determined by two-factor transformation crosses. Cotransformation frequencies shown are means of two or more crosses. Saturating concentrations of DNA were used in all cases except for crosses involving gtaB and $t a g-1$ markers, i.e. when tag $^{+}$recombinants were selected, $0.03 \mu \mathrm{g} \mathrm{DNA} \mathrm{ml} \mathrm{mas}^{-1}$ used. In crosses involving markers $\mathrm{gtaD}, \mathrm{gtaA}, \mathrm{tag}-3$ ( rodCl) and tag-1, co-transfer of unlinked reference markers was in the range $0.01-0.12$. Arrows point from the selected to the co-transferred marker. Linkage between tag-3 and tag- 1 as well as that between $g \operatorname{taD}$ and gtaA corresponds to 1 minus the recombination index.

The data (Table 4) suggested differences in GalN content among group B mutants: two gta $^{9}$ strains, showing sensitivity to phages PBSY and PBSZ, appeared to have slightly higher contents of GalN than a group B mutant resistant to these phages. However, the poor sensitivity of the hexosamine assay prompted a more accurate measurement of this component. Accordingly, cell wall GalN was measured in all mutant classes so far identified. Cultures grown at $37{ }^{\circ} \mathrm{C}$ in the presence of $\left[{ }^{14} \mathrm{C}\right] \mathrm{GlcN} A \mathrm{c}$ were treated to selectively extract GalN from the cellwall fraction (Table 5). Strains containing gtaA or gtaD markers released $20 \%$ of the cell hexosamine, a figure not smaller than that of the wild-type, in agreement with the results in Table 4. Suggested differences (Table 4) in GalN content among gtaB mutants were clearly confirmed with a larger number of strains: whereas, in one group, GalN represented less than $1 \%$ of the wall hexosamines, three $g$ ta $B^{9}$ mutants contained significantly higher $(4 \%)$ amounts of GalN. Likewise, examination of eight mutants in the gtaC-gtaE linkage group revealed that the two $g t a C$ mutations, distinguished from the remaining $g t a E$ mutations by phage sensitivity, were associated with a significant wall GalN content ( 3 and $9 \%)$, whereas this component was $1 \%$ or less in all six gtaE strains. These results and those presented below strongly suggest that the synthesis of one or both GalN-containing polymers can proceed in the absence of either PGM or UDPGPPase, activities essential for glycosylation of the poly(gro $P$ ) teichoic acid (see below).

Transformation and transduction mapping in the gtaA-gtaB and the gtaC regions of the B. subtilis linkage map

Two-point transformation crosses involving relevant markers revealed the likely order gta $B$ gtaD-gtaA-rodC-tag-1 (Fig. 1). The location of gtaD between $g t a B$ and gtaA was confirmed by reciprocal three-factor transformation crosses involving markers gtaDl, gtaA12 and tag- 1 (Table 6). The low numbers of $g t a^{+}$recombinants were due to relatively close linkage of $g t a A$ and gtaD mutations.

The results also revealed that the gtaA (and gtaD) marker was tightly linked to both $t a g-1$ and rodCl (Fig. 1), suggesting close linkage between the latter two markers. This observation 
Table 6. Mapping of gtaD by reciprocal three-factor transformation crosses

DNA was used at saturating concentrations $\left(1-5 \mu \mathrm{g} \mathrm{ml}^{-1}\right)$. Recombinants at the tag- 1 locus obtained by pseudo-linkage were recognized on replica plates of selected leu+ (or met ${ }^{+}$) recombmants at $47^{\circ} \mathrm{C}$.

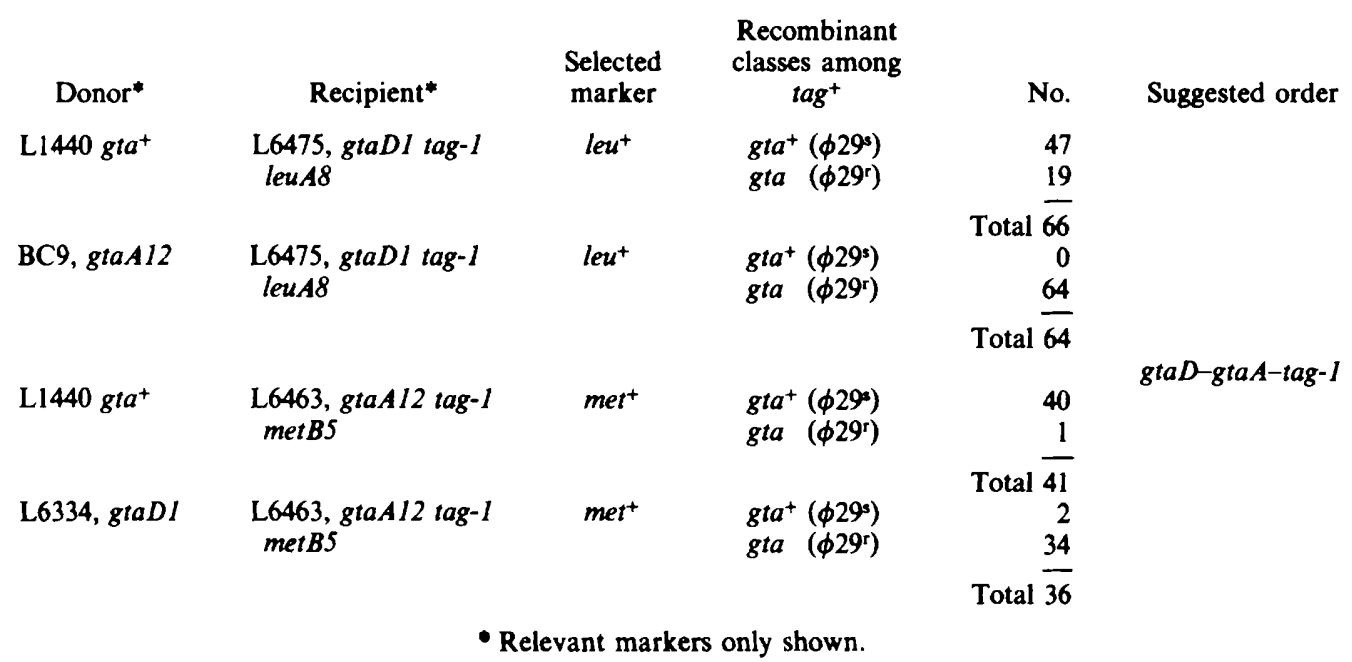

contrasts with a previous study (Karamata et al., 1972) which reported 20\% PRS1 co-transfer of his $\mathrm{A}$ and $\operatorname{rodCl}$, and inferred that the latter marker was widely separated from tag-1. A transformation cross involving rodCl and tag-1 markers gave a recombination index of 0.09 (data not presented), confirming their close linkage. This result, as well as the very similar phenotype of these mutations, prompted the designation tag-3 in place of the previous rodCl.

PBS1 transduction crosses involving gtaC198, gtaE151 and argC4 markers gave $42 \mathrm{gta}^{+}$ recombinants among $684 \mathrm{arg}^{+}$transductants $(6.1 \%)$ with a gtaC donor and a gtaE recipient. In reciprocal crosses, $0 \mathrm{gta}^{+}$recombinants were obtained among $630 \mathrm{arg}^{+}$transductants, establishing the order $g t a C-g t a E-a r g C$.

\section{Assay for UDPGPPase, NADPH oxidase and PGM activities in the soluble fraction of cell extracts}

Identification of mutants affected in glucosylation of poly(gro $P$ ) with new phenotypes distinct phage resistance spectra (Table 3) and chemical composition of the wall (Tables 4 and 5) - as well as genetic evidence suggesting that some linkage groups contained more than one gene, prompted their examination for enzyme deficiencies and, in particular, a search for mutants affected in UDPGPPase activity. However, failure to detect significant UDPGPPase activity in crude cytoplasmic extracts of sonicated cultures of the $\mathrm{gta}^{+}$strain, when prepared as previously described (Young, 1967; Maino \& Young, 1974; Forsberg et al., 1973), led to a search for and identification of appropriate modifications of the assay procedure, i.e. (i) a cell washing step was replaced by rinsing the pellet of harvested cells (see Methods) and (ii) the values for UDPGPPase activity were not corrected for the destruction of NADPH, formed in the assay mixture by the NADPH oxidase activity present in crude cell extracts (Young, 1967).

Cells from representatives of all new and some previously identified gta markers were grown in SAT medium at $37^{\circ} \mathrm{C}$ until the late exponential phase. They were harvested by centrifugation and the cell pellets, after rinsing, were broken by sonication. The soluble fraction was assayed for UDPGPPase and PGM activities (Table 7). It appeared that the UDPGPPase activities in two strains belonging to the $g t a D$ group were not significantly different from that of the gta $^{+}$ strain $\left(6 \cdot 6,7.7\right.$ and 11 units $\mathrm{mg}^{-1}$ protein respectively). A striking result came from the examination of the gtaB linkage group, where among nine strains, including one previously characterized, gtaB290 (Young et al., 1969), not one was found to have a UDPGPPase activity greater than $2 \%$ of that of the wild-type. This strongly suggested that the gene product of the 
Table 7. UDPGPPase and PGM activities in crude extracts of gta mutants

Cell pellets, obtained from late exponential phase cultures grown on SAT at $37{ }^{\circ} \mathrm{C}$, were rinsed with water $\left(0^{\circ} \mathrm{C}\right)$, but not washed, before being broken by sonication. Soluble extracts were assayed immediately after removal of cell debris. Values shown were not corrected for the destruction of NADPH by NADPH oxidase present in extracts.

\begin{tabular}{|c|c|c|c|c|}
\hline \multirow[b]{3}{*}{ Strain } & \multirow[b]{3}{*}{ Marker } & \multicolumn{3}{|c|}{ Enzyme activity [units (mg protein) $\left.)^{-1}\right]^{*}$} \\
\hline & & \multirow[b]{2}{*}{ UDPGPPase } & \multicolumn{2}{|c|}{ PGM } \\
\hline & & & Method $a$ & Method $b$ \\
\hline M22 & $g t a^{+}$ & 11 & $13 \cdot 6$ & 97 \\
\hline $\begin{array}{l}\text { L6334 } \\
\text { L6256 }\end{array}$ & $\begin{array}{l}\text { gtaDI } \\
\text { gtaD2 }\end{array}$ & $\begin{array}{l}7 \cdot 7 \\
6 \cdot 2\end{array}$ & $\begin{array}{l}10 \cdot 9 \\
10 \cdot 5\end{array}$ & \\
\hline $\begin{array}{l}\text { L6331 } \\
\text { L6145 } \\
\text { L6240 } \\
\text { L6254 } \\
\text { L6200 } \\
\text { L6220 } \\
\text { L6238 } \\
\text { L6222 } \\
\text { OB510 }\end{array}$ & $\begin{array}{l}\text { gtaB515 } \\
\text { gtaB } 114 \\
\text { gtaB } 116 \\
\text { gtaB } 123 \\
\text { gta } B^{9} 100 \\
\text { gta } B^{9} 101 \\
\text { gta } B^{9} 102 \\
\text { gta } B^{9} 103 \\
\text { gta } B 290\end{array}$ & $\begin{aligned} \leqslant 0 \cdot 1 \\
\leqslant 0 \cdot 1 \\
\leqslant 0 \cdot 1 \\
\leqslant 0 \cdot 1 \\
\leqslant 0.1 \\
0.14 \\
\leqslant 0.1 \\
\leqslant 0.1 \\
\leqslant 0.1\end{aligned}$ & $\begin{array}{r}13 \cdot 1 \\
9 \cdot 5 \\
11 \cdot 4 \\
7 \cdot 3 \\
20 \cdot 4 \\
9 \cdot 6 \\
7 \cdot 3 \\
8 \cdot 3 \\
N D\end{array}$ & 140 \\
\hline $\begin{array}{l}\text { L6118 } \\
\text { L6119 } \\
\text { L.6125 } \\
\text { L6170 }\end{array}$ & $\begin{array}{l}\text { gtaEIS1 } \\
\text { gtaE } 152 \\
\text { gtaE } I 58 \\
\text { gtaE } 180\end{array}$ & $\begin{array}{l}0.8 \\
0.8 \\
0.5 \\
0.7\end{array}$ & $\begin{array}{l}<1 \\
<1 \\
<1 \\
<1\end{array}$ & 13 \\
\hline $\begin{array}{l}\text { L6179 } \\
\text { L6188 }\end{array}$ & $\begin{array}{l}\text { gtaC } 189 \\
\text { gtaC } 198\end{array}$ & $\begin{array}{l}12 \\
5 \cdot 6\end{array}$ & $\begin{array}{l}<1 \\
<1\end{array}$ & \\
\hline BC7 & gtaC5I & 6.9 & $<1$ & \\
\hline
\end{tabular}

ND, Not done.

- In the majority of cases results represent the mean of a minimum of two experiments.

gtaB locus was indeed the UDPGPPase activity, as originally supposed by Young (1967). Possible reasons for the apparent contradiction, i.e. the failure (Young, 1967; Yasbin et al., 1976) to detect in vitro such a deficiency are examined in the Discussion. Finally, assay of this activity in seven strains with the gtaC or gtaE markers, including the previously characterized mutation gtaC51 (Young, 1967), revealed that gtaC strains had activities comparable to the gta $^{+}$ value, while the $g t a E$ strains had only $5-10 \%$ of this value.

The NADPH oxidase activity present in cell extracts (Young, 1967) degrades the NADPH formed during the reaction and thus could affect the measured UDPGPPase (see Methods). Loss of $A_{340}$ after addition of NADPH to cell extracts ( $2 \mathrm{mg}$ protein), allowed measurement of this activity. The latter was found (not shown) to be (i) virtually identical for all strains shown in Table 7 and (ii) proportional to the initial concentration of added NADPH up to $0 \cdot 2 \mu \mathrm{mol} \mathrm{ml}-1$ $\left(A_{3+0} 1 \cdot 2\right)$. At the latter concentration the rate of NADPH destruction was equivalent to 10 units per mg protein of the extract, i.e. comparable to the UDPGPPase activity present in the $g^{+} a^{+}$ organism. However, for smaller initial concentrations of NADPH, in the range $0 \cdot 1-0 \cdot 2 A_{340}$ units, the measured NADPH oxidase was at least five times lower than that of NADPH formation in the UDPGPPase assay of strains not deficient in the latter activity. As the rate of destruction was concentration dependent, correction for NADPH destruction was difficult and was thus omitted. For strains deficient in UDPGPPase activity, where the increase in $A_{340}$ was nil or extremely low, the absence of NADPH oxidase activity, being dependent on NADPH concentration, rendered correction for NADPH destruction unnecessary.

In confirmation of previous findings, only strains belonging to the gtaC-gtaE linkage group showed significant deficiency in PGM activity (Table 7). 


\section{DISCUSSION}

The attempt here to isolate new markers involved in wall teichoic acid synthesis in $B$. subtilis by exploiting, as done previously, the resistance to, principally, phage $\phi 29$ was successful to a very limited extent. Mutations in over 150 strains (Table 2 and not shown) mapped close to previously identified markers $g t a A, g t a B$ and $g t a C$. On the one hand this is not surprising since we have shown (Karamata et al., 1987) that most if not all teichoic acid genes are located in the his $A$ region. Nevertheless, genetic, chemical and phage-resistance analyses have revealed the existence of new markers with distinct phenotypes in all three linkage groups. In two of them, gta $A$ and $g t a C$, the evidence strongly suggests the presence of more than one gene.

Two closely linked mutations, clearly separated from a $\mathrm{gtaA}$ reference marker and with a distinct phage resistance spectrum, have been assigned to a new group, gtaD. Like gtaA mutants, they are characterized by a deficiency of cell-wall glucose and normal activities of PGM and UDPGPPase. We have not determined whether gta $D$ mutations affect the UDPG: poly(gro $P)$ glucosyltransferase, shown to be deficient in previously identified gtaA mutants (Young, 1967).

All mutations linked to the previously identified marker gtaC5I conferred a considerably reduced PGM activity. Two of them, gtaC189 and gtaC198, located at one extremity of this group, are characterized by wild-type levels of UDPGPPase, a significant cell wall GalN content and sensitivity to phage PBSZ. However, the majority of these mutants showed decreased UDPGPPase activity (about 5-10\% of that of the wild-type), absence of GalN, and resistance to all phages. It is likely that the latter class maps in a regulatory gene, designated gtaE, which controls the level of both PGM and UDPGPPase. Mutant BC7, containing gtaC51 (Young, 1967), is an exception since it has normal UDPGPPase activity but, like gtaE mutants, lacks wall GalN and is resistant to PBSZ. Genetic analysis suggests that it harbours more than one linked gta mutation (data not presented).

The most surprising finding concerns the probable identification of the gene product of the gtaB locus as UDPGPPase. This activity is strongly deficient or absent in all of the nine probably independent $g t a B$ or gtaB $B^{9}$ mutants examined, including one, gtaB290, described previously (Young, 1967); it is 5- to 10-fold lower than that characteristic of gtaE mutants (see above). These results are in apparent contradiction with previous findings, where UDPGPPase activity was found to be normal in all gtaB mutants examined (Young, 1967; Yasbin et al., 1976). We believe that the explanation could well lie in the unwarranted (see Results) application of a correction for NADPH oxidase to extracts that had little UDPGPPase activity. Indeed, when using a cell washing step, as previously described (Young, 1967; Maino \& Young, 1974), we failed to obtain extracts with UDPGPPase activity (see Methods). It has been reported that use of certain buffers for extract preparation leads to inactivation of this enzyme in extracts from the slime mould Dictyostelium discoideum (Newell \& Sussman, 1969; Edmundson \& Ashworth, 1972). Introduction of a correction for NADPH oxidase activity during assay of extracts with residual UDPGPPase activity not only accounts for reported activities but is also consistent with the strikingly similar values for all strains examined in previous studies. Indeed, a virtually identical NADPH oxidase activity was obtained in all mutants examined here. Also consistent with the above interpretation are the activities reported here for the wild-type, which, compared to previous results, are broadly similar for PGM but, without any corrections are approximately threefold higher for UDPGPPase.

The specific requirement for glucosylated poly $(g r o P)$ for adsorption of $\phi 29$ provides the most likely explanation for the failure to identify, among mutants resistant to this phage, more new markers affecting teichoic acid synthesis. In particular, it would account for the absence of mutants specifically blocked in the synthesis of other teichoic acids present in the cell wall of this organism (Duckworth et al., 1972; Shibaev et al., 1973). However, the heterogeneity among gta mutants with respect to GalN-containing polymers cannot be easily correlated with observed enzyme deficiencies. Understanding of this question would require a more complete knowledge of the structure and biosynthesis of GalN-containing polymers (Shibaev et al., 1973). Previous results (Archibald, 1980), as well as those reported here, provide good grounds for believing that the latter polymers form part of the receptors for other bacteriophages, PBSZ for example. 
The most notable absence among mutants isolated both here and previously is that of mutations blocking synthesis of the main polyolphosphate chain, since they should be equally resistant to $\phi 29$. This absence supports previously presented evidence (Karamata et al., 1987) that many such mutations are lethal, and is in favour of an essential role for this polymer in cell growth. Indeed, conditional lethal mutants genes which, when mutated, express a conditional lethal phenotype (as exemplified by tag- 1 and tag-3 mutations) are very good candidates for being involved in the biosynthesis of the main polyolphosphate chain (Karamata et al., 1987). Furthermore, the evidence obtained that $\operatorname{tag}-1$ is affected in poly(gro $P$ ) synthesis strongly suggests that deficiencies in the synthesis of this polymer lead to disturbances in cell shape and in the orderly process of surface growth. It would appear that the majority of morphologically disturbed mutants known in $B$. subtilis harbour mutations that now map where most - if not all teichoic acid genes have been recently mapped (Karamata $e t$ al., 1987). This underlines how much remains to be learnt both of the genetic regulation of the biosynthesis and of the roles of the anionic cell wall polymers in $B$. subtilis, and in other Gram-positive organisms.

We are grateful to Dr Cyrille Brandt for helpful suggestions concerning the wall analyses and to Dr C. Bergerioux of the Institut de Médecine légale, Lausanne, for the use of gas chromatographs. We thank Dr F. Fiedler for kindly performing several wall analyses. The competent technical help of Patrick Lüscher and Nadia De Icco is gratefully acknowledged. Some of the present results have been reported in the form of a diplôme (D. Paschoud) of the University of Lausanne, 1983.

\section{REFERENCES}

AMES, B. N. \& DUBIN, D. T. (1960). The role of polyamines in the neutralisation of bacteriophage deoxyribonucleic acid. Journal of Biological Chemistry 235, 769-775

ARChibald, A. R. (1974). The structure, biosynthesis and function of teichoic acid. Advances in Microbial Physiology 11, 53-95.

ARCHibald, A. R. (1980). Phage receptors in Grampositive bacteria. In Virus Receptors (Receptors and Recognition, Series B, vol. 7), pp. 7-26. Edited by L. L. Randall \& L. Philipson. London: Chapman \& Hall.

BADDILEY, J. (1970). Structure, biosynthesis and function of teichoic acids. Accounts of Chemical Research 3, 98-105.

Bodmer, W. F. \& Ganesan, A. T. (1964). Biochemical and genetic studies of integration and recombination in Bacillus subtilis transformation. Genetics 50, 717738 .

Boylan, R. J., Mendelson, N. H., Brooks, D. \& YouNG, F. E. (1972). Regulation of the bacterial cell wall: analysis of a mutant of Bacillus subtilis defective in biosynthesis of teichoic acid. Journal of Bacteriology 110, 281-290.

BRADFORD, M. M. (1976). A rapid and sensitive method for the quantitation of microgram quantities of protein utilising the principle of protein-dye binding. Analytical Biochemistry 72, 248-254.

Deckworth, M., Archibald, A. R. \& Baddiley, J. (1972). The location of $\mathrm{N}$-acetylgalactosamine in the walls of Bacillus subtilis 168. Biochemical Journal 130, 691-696.

EDMundson, T. D. \& AshWORTH, J. (1972). 6Phosphogluconate dehydrogenase and the assay of uridine diphosphate glucose pyrophosphorylase in the cellular slime mould Dictyostelium discoideum. Biochemical Journal 126, 593-600.

ForsberG. C. W., WYrick, P. B., WARD, J. B. \& ROGERS, H. J. (1973). Effect of phosphate limitation on the morphology and wall composition of Bacillus licheniformis and its phosphoglucomutase-deficient mutants. Journal of Bacteriology 113, 969-984.

Givan, A. L., Glassey, R. S., Green, W. K., Lang, A. J. \& ARCHIBALD, A. R. (1982). Relation between wall teichoic acid content of Bacillus subtilis and efficiency of adsorption of bacteriophages SP50 and $\phi 25$. Archives of Microbiology 133, 318 $\div 322$.

HENNER, D. J. \& Hoch, J. A. (1980). The Bacillus subtilis chromosome. Microbiological Reviews 44, 5782.

KALCKAR, H. M. (1955). Enzymatic determination of UDPG by the specific pyrophosphorylase. Methods in Enzymology 2, 676-677.

Karamata, D. \& Gross, J. D. (1970). Isolation and genetic analysis of temperature sensitive mutants of Bacillus subtilis defective in DNA synthesis. Molecular and General Genetics 108, 277-287.

Karamata, D., McConnell, M. \& Rogers, H. J. (1972). Mapping of rod mutants of Bacillus subtilis. Journal of Bacteriology 111, 73-79.

Karamata, D., Pooley, H. M. \& Monod, M. (1987). Expression of heterologous genes for wall teichoic acid in Bacillus subtilis 168. Molecular and General Genetics 207, 73-81.

Maino, V. C. \& Young, F. E. (1974). Regulation of glucosylation of teichoic acid. Isolation of phosphoglucomutase in Bacillus subtilis 168. Journal of Biological Chemistry 249, 5169-5175.

Mauël, C. \& Karamata, D. (1984). Prophage induction in thermosensitive DNA mutants of Bacillus subtilis. Molecular and General Genetics 194, 451-456.

Mishra, N. C. \& TAtum, E. L. (1970). Phosphoglucomutase mutants of Neurospora sitophila and their relation to morphology. Proceedings of the National Academy of Sciences of the United States of America 66, 638-645.

Newell, P. C. \& Sussman, M. (1969). Uridine diphosphate glucose pyrophosphorylase in Dictyo- 
stelium discoideum. Journal of Biological Chemistry 244, 2990-2995.

Pavlik, J. G. \& Rogers, H. J. (1973). Selective extraction of polymers from cell walls of Gram positive bacteria. Biochemical Journal 131, 619-621.

POOLEY, H. M. (1976). Turnover and spreading of old wall during surface growth of Bacillus subtilis. Journal of Bacteriology 125, 1127-1138.

PoOley, H. M. \& Karamata, D. (1984). Genetic analysis of lytic deficient and flagellaless mutants in Bacillus subtilis. Journal of Bacteriology 160, 11231129.

Schlaeppi, J.-M., Pooley, H. M. \& Karamata, D. (1982). Identification of cell wall subunits in Bacillus subtilis and analysis of their segregation during growth. Journal of Bacteriology 149, 329-337.
Shibaev, V. N., Duckworth, M., ArChibald, A. R. \& BADDILEY, J. (1973). Structure of a polymer containing $N$-acetylgalactosamine from walls of Bacillus subtilis 168. Biochemical Journal 135, 383-384.

Yasbin, R. E., Maino, V. C. \& Young, F. E. (1976). Bacteriophage resistance in Bacillus subtilis 168 , W23 and interstrain transformants. Journal of Bacteriology 125, 1120-1126.

YouNG, F. E. (1967). Requirement of glucosylated teichoic acid for adsorption of phage in Bacillus subtilis 168. Proceedings of the National Academy of Sciences of the United States of America 58, 23772384.

Young, F. E., Smith, C. \& ReIlly, B. E. (1969). Chromosomal location of genes regulating resistance to bacteriophage in Bacillus subtilis. Journal of Bacteriology 98, 1087-1097. 